\title{
Secretion of Catecholamines in Malignant Phaeochromocytoma
}

\author{
R. ROBINSON,* B.SC., PH.D., F.R.I.C. ; P. SMITH, $\dagger$ B.SC., PH.D., D.I.C. \\ S. R. F. WHITTAKER, $\ddagger$ M.D., F.R.C.P.
}

Brit. med. F., 1964, 1, 1422-1424

Phaeochromocytomas are usually benign tumours but they can be malignant, and some which are at first thought to be benign recur and metastasize (Kvale et al., 1954). Since assessment of malignancy may be impossible by histological methods in the absence of metastases (Symington and Goodall, 1953), there is a need for some method or test that will determine whether the surgical removal of a phaeochromocytoma will lead to a cure or whether a recurrence is likely.

Davis et al. (1955) suggested that the pressor amines should be estimated during the post-operative period, and if a persistently increased quantity is found it is probable that there is a second primary tumour or that the original tumour was melignant and had already metastasized.

We report a case where the secretion of pressor amines was normal for 11 months after the removal of a phaeochromocytoma, but an increase then occurred and death quickly followed from multiple secreting metastases.

In a series of 36 phaeochromocytoma patients whose urinary phenols we have studied, the urine of this patient alone contained appreciably abnormal amounts of dopamine metabolites (3-methoxytyramine and homovanillic acid) and, so far as can be ascertained, no other subject was suffering from a malignant phaeochromocytoma.

McMillan (1956) first suggested that malignant phaeochromocytomas selectively secrete dopamine, but Kennedy et al. (1961) could find no dopamine or dopa by chromatography in the primary growth of a malignant phaeochromocytoma. Biochemical studies on our patient support McMillan's view and suggest that the presence of abnormally large amounts of dopamine metabolites in the urine of a phaeochromocytoma patient is good evidence that the tumour is malignant.

\section{Methods}

Free catecholamines were estimated in urine by the method of Hingerty (1957). Since endogenous catecholamines are almost completely metabolized, examination of the metabolites rather than the small amount of unchanged catecholamines affords a more faithful reflection of overall metabolism. For this reason we have studied in some detail the excretion of these metabolites, using chromatographic methods. The results are expressed semi-quantitatively in the Table and were obtained by visual inspection of two-way chromatograms. Details of the methods have been described elsewhere (Robinson et al., 1959 ; Robinson and Smith, 1962).

The main pathways of biosynthesis and metabolism of the catecholamines are well known and are summarized in simplified form in the accompanying Chart.

\section{Case History}

A man aged 51 was admitted to hospital complaining of attacks of sweating, general weakness, and palpitations at irregular intervals

^ Biochemist, Warwick Hospital.

+ Senior Scientific Officer, R.A.F. Institute of Aviation Medicine, Farnborough. for 12 years. He had consulted several doctors, and at one time had been diagnosed as suffering from essential hypertension because his blood-pressure was 200/128 mm. Hg. In July 1960 he had a particularly severe attack of sweating with marked flushing of the face, neck, and shoulders. His general practitioner thought that he might have a phaeochromocytoma because of the similarity of the clinical picture to a case occurring in the same practice a year previously (Stephens, 1961).

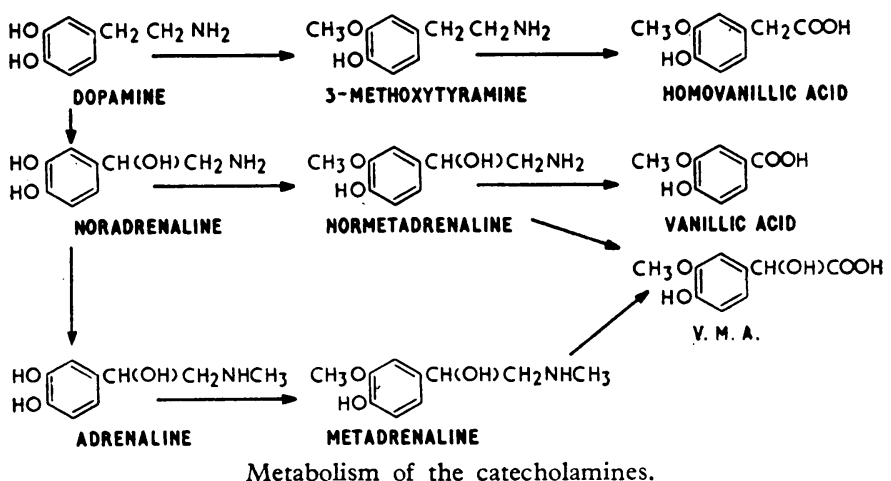

On admission his appearance was remarkable; there was intense flushing of the face and upper part of the chest, together with vasospasm and associated blueness and coldness of the legs. Sweat was pouring off the face and the conjunctivae were crimson. The pulse was 120 and blood-pressure $150 / 110$. A mass about the size of an orange was felt in the right side of the abdomen. An intravenous pyelogram showed that the right renal pelvis was small, with distorted calices in keeping with a large tumour of the suprarenal. The blood urea was $33 \mathrm{mg} . / 100 \mathrm{ml}$.

An intravenous phentolamine test was positive and the urinary catecholamine excretion was greater than $1,000 \mu \mathrm{g} . / 24$ hours. Chromatographic examination of the urine showed a gross derangement of tyrosine metabolism (Sample 1 in Table). Catecholamine metabolites excreted in large quantities included VMA (4-hydroxy3-methoxymandelic acid), homovanillic acid, vanillic acid, metadrenaline, normetadrenaline, $\mathrm{N}$-methyl metadrenaline, and 3-methoxytyramine; the tyrosine metabolite $p$-hydroxyphenyllactic acid was also excreted in large quantities.

At operation a large phaeochromocytoma $12 \mathrm{~cm}$. in diameter and weighing $900 \mathrm{~g}$. was removed with some difficulty; the postoperative phase was stormy, with a period of anuria. However, the

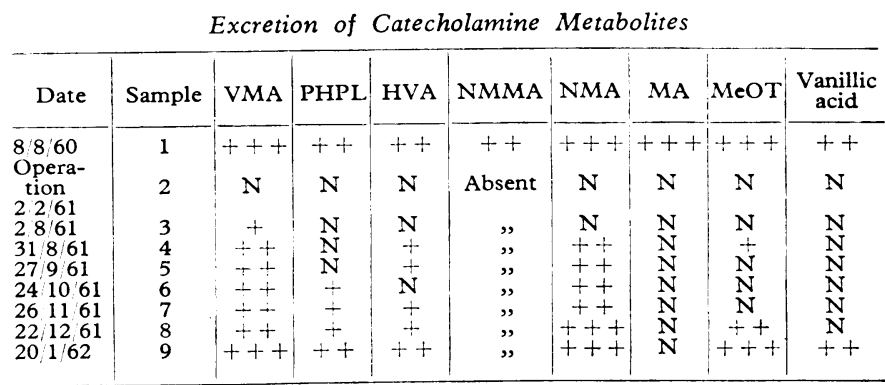

VMA $=4$-hydroxy-3-methoxymandelic acid. PHPL $=p$-hydroxyphenyllactic acid. HVA $=$ Homovanillic acid. NMMA $=\mathrm{N}$-methyl metadrenaline. NMA Normetadrenaline. $\mathrm{MA}=$ Metadrenaline. $\mathrm{MeOT}=3$-methoxytyramine Normal. + Possibly above normal 
patient was discharged from hospital a month later and soon returned to work. The facial flush completely disappeared.

Histological examination of the tumour suggested that it was a benign phaeochromocytoma enclosed in a thin capsule, which was apparently intact and not invaded by tumour cells.

\section{Progress}

The patient attended the out-patient clinic at regular intervals; he appeared to be in excellent health and was at work for 11 months. $\mathrm{He}$ had no attacks of sweating and the blood-pressure remained around $150 / 90$.

The urinary excretion of free catecholamines and their metabolites fell to normal and remained so for some months.

In August 1961, 11 months after the operation, a specimen of urine was examined and the V.M.A. excretion was found to be on the upper limit of normality (Sample 3 in Table). About the same time the patient began to complain of headache and pain in the left arm and right shoulder. The blood-pressure rose to $190 / 110$ and the blood urea was $37 \mathrm{mg} . / 100 \mathrm{ml}$.

A month later a further urine specimen showed a significant increase in the excretion of VMA and normetadrenaline. Radiographs of the skeleton revealed osteolytic lesions in the left lower scapula and the right clavicle. The facial flush returned and the patient again began to sweat profusely.

Deep $x$-ray therapy was given to the areas of the bony lesions, but progress was downhill, with enlargement of the liver, and death occurred in January 1962.

During the last two months of life there was a gradual increase in the excretion of catecholamine metabolites (Samples 7 to 9). The dopamine metabolites 3-methoxytyramine and homovanillic acid appeared in the urine in the last few weeks before the patient's death. Large amounts of vanillic acid and p-hydroxyphenyllactic acid were also present.

Just before the patient's death the biochemical picture was exactly similar to that immediately before the removal of the primary tumour except for the striking absence of abnormal quantities of metadrenaline and $\mathrm{N}$-methyl metadrenaline.

\section{Necropsy}

At necropsy (Dr. M. K. Alexander) the liver was greatly enlarged and infiltrated with nodules of growth measuring up to $5 \mathrm{~cm}$. in diameter. Secondary deposits were also present in the body of the second thoracic vertebra, the lower part of the left scapula, the seventh right rib, and the eleventh left rib. Deposits were also found in the lumbar lymph nodes bilaterally, and a solitary nodule about $3 \mathrm{~cm}$. in diameter was present in the approximate site of the right adrenal. No deposits were found in the left adrenal or the lungs.

\section{Discussion}

Malignant phaeochromocytomas are extremely rare and few opportunities have arisen to conduct biochemical studies on patients suffering from these tumours.

So far as we are aware, the only other reported study of catecholamine excretion by a patient with a malignant phaeochromocytoma is that of Davis et al. (1955). These workers found that the excretion of catecholamines remained high after the removal of the primary tumour. This was because the tumour had metastasized and the secondary growths were functionally active at the time of the operation.

In this respect our patient was different. The excretion of catecholamines and their metabolites became normal after the removal of the primary tumour, and it thus follows that at this time the metastases were not yet functionally active. It was not until 11 months later that both clinical and biochemical evidence indicated that the metastases were growing rapidly and had started to secrete catecholamines. We thus had an unusual opportunity of studying separately the secretory activities of the primary tumour and the secondary growths.
Chromatographic examination of the urine specimen collected on the patient's first admission to hospital showed that the primary tumour was extremely active. The urine contained very large quantities of the catecholamine metabolites normetadrenaline, metadrenaline, N-methyl metadrenaline, vanillylmandelic acid (VMA), homovanillic acid, and 3-methoxytyramine (see Table). This rather bizarre pattern of metabolites indicates that the tumour secreted at least four catecholamines-namely, noradrenaline, adrenaline, N-methyladrenaline, and dopamine. The outstanding finding was the large quantity of dopamine metabolites.

We have recently examined urine specimens from 35 other patients with phaeochromocytomas. So far as we have been able to ascertain, none of these patients had a malignant tumour, and none excreted grossly increased amounts of dopamine metabolites.

M. Sandler and C. R. J. Ruthven (personal communication, 1962) have also found an increased excretion of dopamine metabolites in a patient with a malignant phaeochromocytoma, but they believed this was a terminal event. Nevertheless, both our results and those of Sandler and Ruthven are in accord with McMillan's (1956) suggestion that malignant phaeochromocytomas selectively secrete dopamine.

When-our patient's metastases became functionally active it was at once apparent that there was a striking difference in secretory activity of the primary and secondary growths. Though the primary tumour secreted both adrenaline and $\mathrm{N}$-methyladrenaline, the secondary growths appeared to secrete neither and seemed unable to $\mathrm{N}$-methylate noradrenaline. It is of some interest to speculate on the significance of this observation.

Not all chromaffin cells have the ability to $\mathrm{N}$-methylate noradrenaline. There appears to be some correlation between the maturity of the tissue and the ability to convert noradrenaline to adrenaline. Primitive chromaffin tissue such as the foetal adrenal medulla and the organs of Zuckerkandl at birth contains chiefly noradrenaline and little, if any, adrenaline (West et al., 1953). The ability to synthesize adrenaline in the adrenal medulla develops rather gradually during childhood. It is possible, therefore, that the inability of the metastases to $\mathrm{N}$-methylate noradrenaline is an indication that the tissue was relatively more primitive than the primary growth.

The pattern of excretion of catecholamine metabolites in the terminal stages was strikingly reminiscent of that observed in patients with functionally active neuroblastomas (Robinson and Smith, 1960 ; von Studnitz, 1960 ; Voorhess and Gardner, 1962 ; Bell, 1963). These patients also excrete large quantities of dopamine metabolites as well as noradrenaline metabolites.

Since neuroblastomas are invariably malignant, it seems possible that all malignant tumours of sympathetic tissues may secrete dopamine. Obviously, more study is required on this point, but it might be worth while examining urine specimens from all patients with phaeochromocytomas for the dopamine metabolites homovanillic acid and 3-methoxytyramine. If these are increased in amount its seems likely that the tumour will prove to be malignant.

\section{Summary}

A study was made of the excretion of catecholamines and their metabolites by a patient with a malignant phaeochromocytoma.

After the surgical removal of the primary tumour the excretion of catecholamines and their metabolites became normal and remained so for 11 months. Excretion values then rose rapidly to very high levels and the patient died of multiple secreting metastases. 
It is suggested that the excretion of large amounts of dopamine metabolites, homovanillic acid, and 3-methoxytyramine may indicate that the phaeochromocytoma is malignant.

\section{REFERENCES}

Bell, M. (1963). In Clinical Chemistry of Monoamines. Elsevier, Amsterdam.

Davis, P., Peart, W. S., and van't Hoff, W. (1955). Lancet, 2, 274.

Hingerty, D. (1957). Ibid., 1, 766.

Kennedy, J. S., Symington, T., and Woodger, B. A. (1961). F. Path. Bact., 81, 409.
Kvale, W. F., Priestley, J. T., and Roth, G. M. (1954). Arch. Surg., 68, 769.

McMillan, M. (1956). Lancet, 2, 284.

Robinson, R., Ratcliffe, J., and Smith, P. (1959). F. clin. Path., 12, 541. and Smith, P. (1960). Nature (Lond.), 186, 240.

Step (1962). Clin. chim. Acta, 7, 29.

Studnitz, W. von (1960). Scand. 7. clin. Lab. Invest., 12, Suppl. No. 48, p. 3 .

Symington, T., and Goodall, A. L. (1953). Glasg. med. 7., 34, 75.

Voorhess, M. 'L., and Gardner, L. I. (1962). f. clin. Endocr., 22, 126.

West, G. B., Shepherd, D. M., Hunter, R. B., and Macgregor, A. R. (1953). Clin. Sci., 12, 317 .

\title{
Conversion After Freeze-dried B.C.G.
}

\author{
K. NEVILLE IRVINE,* D.M.; A. BARR, † M.SC.
}

Brit. med. F., 1964, 1, 1424-1425

If it can be shown that the appearance of a local reaction at the site of vaccination can be regarded as a criterion of successful B.C.G. vaccination, as is the accepted practice in vaccination against smallpox, the time and money spent on post-vaccination testing and reading would be saved. In an earlier paper (Irvine and Barr, 1960) we showed that $99.6 \%$ of 13-year-old schoolchildren who developed a papule at the site of vaccination after intracutaneous Danish fresh (liquid) B.C.G. converted from Heaf-negative to Heaf-positive. From this we concluded: "The presence of any local reaction to intracutaneous vaccination with Danish fresh vaccine may be regarded as an indication of successful vaccination. Only persons with no local reaction to vaccination require a conversion test."

The short life of fresh vaccine and its heat-sensitivity raised transport problems which severely limited its use, especially in the tropics. The introduction of a reliable freeze-dried B.C.G. which is more heat-stable and has a life of 12 months has been a great advance. This is a report of a trial similar to the earlier one with Danish fresh vaccine but using British freeze-dried vaccine.

\section{Material and Method}

The analysis is based on 11,199 vaccinations carried out during the school year 1960-1. A Heaf test was given before and after vaccination; the standard Heaf P.P.D. issued by the Ministry of Health was used and the test was normally read at seven days as recommended by the British Tuberculosis Association (1959), though readings up to 10 days were accepted. The apparatus used was East's automatic gun with a de Hamel nose-piece. ${ }^{1}$ Induration at the site of four of the six punctures was the minimum criterion of a positive reaction. Negative reactors to the pre-vaccination Heaf test were given $0.1 \mathrm{ml}$. of reconstituted Glaxo freeze-dried vaccıne intracutaneously by some 50 school medical officers. Fortytwo batches were used whose viable counts ranged from $4.0 \times 10^{6}$ to $12.8 \times 10^{6}$. The post-vaccination Heaf test was carried out 35 to 63 days after vaccination and was read at 42 to 70 days. In one school 29 children had to be tested at 34 days and read at 41 days; they all proved positive. The

$\star$ Medical Director, B.C.G. Control Centre, Henley-on-Thames. + Statistician, Oxford Regional Hospital Board.

${ }^{t}$ Made by Messrs. H. G. East and Co. Ltd., 37a Oxford Road, Cowley, Oxford. local reaction to vaccination was inspected when the postvaccination Heaf test was read, and the mean width of the indurated papule in millimetres was measured with callipers. None of the children was in contact with known open tuberculosis at the time of vaccination.

The work was carried out by the B.C.G. Control Centre. This was set up in 1958 at the request of the Ministry of Health when Glaxo freeze-dried vaccine was first released for use in this country, so that the laboratory control of each batch could also be checked clinically. The results were collated and analysed by the Regional Records Department of the Oxford Regional Hospital Board. The clinical work of the Control Centre was carried out by the medical officers of health and school medical officers listed below.

\section{Results}

Of the 11,199 children vaccinated 10,893 converted, giving a conversion rate of $97.3 \%$. As will be seen from Table I, the differences between the conversion rates recorded at different intervals after vaccination showed no obvious trend - so confirming that this is a satisfactory range of time for post-vaccination testing. However, reports from vaccinators suggested that there was a small proportion of schoolchildren who converted late after dried vaccine. It was therefore decided to retest as many of the 306 non-converters as possible when the next B.C.G. session was carried out at each school.

TABLE I.-Width of Vaccination Reaction and Conversion Rate Read at

\begin{tabular}{|c|c|c|c|c|c|}
\hline $\begin{array}{c}\text { Days after } \\
\text { Vaccina- } \\
\text { tion }\end{array}$ & $\begin{array}{c}\text { No. of } \\
\text { Vaccina- } \\
\text { tions }\end{array}$ & $\begin{array}{l}\text { Mean Width } \\
\text { of Indurated } \\
\text { Papule (mm.) }\end{array}$ & $\begin{array}{c}\text { Standard } \\
\text { Error of } \\
\text { Mean (mm.) }\end{array}$ & $\begin{array}{l}\text { Standard } \\
\text { Deviation }\end{array}$ & $\begin{array}{c}\text { Conversion } \\
\text { Rates } \\
(\%)\end{array}$ \\
\hline $\begin{array}{l}<43 \\
43- \\
50- \\
57- \\
64-70\end{array}$ & $\begin{array}{l}1,812 \\
3,331 \\
2,789 \\
1,885 \\
1,382\end{array}$ & $\begin{array}{l}9 \cdot 18 \\
9.58 \\
9.11 \\
8.44 \\
9 \cdot 11\end{array}$ & $\begin{array}{l}0.07 \\
0.06 \\
0.06 \\
0.08 \\
0.09\end{array}$ & $\begin{array}{l}2.86 \\
3.56 \\
3.39 \\
3.57 \\
3.23\end{array}$ & $\begin{array}{l}95.6 \\
98.0 \\
97.6 \\
96.4 \\
98.2\end{array}$ \\
\hline All & 11,199 & $9 \cdot 15$ & 0.03 & $3 \cdot 40$ & $97 \cdot 3$ \\
\hline
\end{tabular}

As was to be expected, some of the 306 non-converters had left school by the next visit; nevertheless the school medical officers succeeded in testing $239(78.1 \%)$. Of these, 183 $(76.6 \%)$ were found to be positive and 56 negative. These retests were carried out 5 to 17 months after vaccination with 